\title{
Phytochemical composition and health properties of Sembung plant (Blumea balsamifera): A review
}

\author{
I. Gede Widhiantara ${ }^{1,2}$ iD and I. Made Jawi ${ }^{3}$ iD
}

1. Medical Science Study Program, Faculty of Medicine, Udayana University, Jalan P.B. Sudirman, Denpasar City, Bali Province 80234, Indonesia; 2. Study Program of Biology, Faculty of Health, Science, and Technology, Dhyana Pura University, Jalan Raya Padang Luwih, Dalung, North Kuta, Badung, Bali Province 80361, Indonesia; 3. Department of Pharmacology, Faculty of Medicine, Udayana University, Jalan P.B. Sudirman, Denpasar City, Bali Province 80234, Indonesia.

Corresponding author: I. Gede Widhiantara, e-mail: widhiantara@undhirabali.ac.id

Co-author: IMJ: made_jawi@yahoo.co.id

Received: 04-12-2020, Accepted: 25-03-2021, Published online: 17-05-2021

doi: www.doi.org/10.14202/vetworld.2021.1185-1196 How to cite this article: Widhiantara IG, Jawi IM (2021) Phytochemical composition and health properties of Sembung plant (Blumea balsamifera): A review, Veterinary World, 14(5): 1185-1196.

\begin{abstract}
Indonesia's mindset has been focusing on the use of natural medicines, food, and healing practices widely recognized by the nation's culture. Traditional medicines and herbs used in traditional medicine can often lead to the discovery of drugs against certain diseases. The aim of this review was to study evidence-based data on the importance of Sembung plant, Blumea balsamifera, as a potential traditional medicine. The distribution, ethnopharmacology, secondary metabolites, and bioactivity against several diseases are focused in this review. Information and research related to Sembung plant were searched using the terms "B. balsamifera," "phytochemicals," and "pharmacological activity" on ResearchGate, Google Scholar, Science Direct, PubMed, and scientific information-based databases up to 2020. Several ethnomedical articles recommend B. balsamifera for the treatment of sinusitis, colic pain, cough, kidney stones, flu, or as a diuretic. This knowledge has already been applied in several countries in Southeast Asia. B. balsamifera has been reported to contain several phytochemicals both volatile (terpenoids, fatty acids, phenols, alcohol, aldehydes, ethers, ketones, pyridines, furans, and alkanes) and non-volatile (flavonoids, flavanones, and chalcones). Extracts and phytochemicals of B. balsamifera contain several biological capacities such as antioxidant, antimicrobial, antifungal, anti-inflammatory, hypolipidemic, antiinfertility, hepatoprotective activity, antidiabetic, gastroprotective, antitumor, anticancer, and immunomodulatory agent against Coronavirus disease-19 infection. This review provides essential data for the potential application of $B$. balsamifera as a nutraceutical or in future medicinal preparations.
\end{abstract}

Keywords: Asteraceae, Blumea balsamifera, future medicine, medicinal uses, phytochemical constituents.

\section{Introduction}

Indonesia has enormous potential for the development of herbal medicines and traditional medicinal preparations that have been already traditionally used to treat various diseases [1]. Apart from Indonesia, the use of traditional medicines has also been developed in other countries of the Southeast Asian Association (ASEAN) in recent years [2]. The use of these traditional plants has been targeting several diseases, from a common cold to cancer [3]. Contemporary research has validated several parts of plants from roots, stems, and leaves in potential medicinal preparations by screening for active ingredients such as plant metabolites [4-6].

Blumea balsamifera (L) DC. (Asteraceae) or known as local Sembung (in Indonesia) has been widely used as a traditional medicinal preparation for thousands of years. Several countries in Southeast

Copyright: Widhiantara and Jawi. Open Access. This article is distributed under the terms of the Creative Commons Attribution 4.0 International License (http://creativecommons.org/licenses/ by/4.0/), which permits unrestricted use, distribution, and reproduction in any medium, provided you give appropriate credit to the original author(s) and the source, provide a link to the Creative Commons license, and indicate if changes were made. The Creative Commons Public Domain Dedication waiver (http:// creativecommons.org/publicdomain/zero/1.0/) applies to the data made available in this article, unless otherwise stated.
Asia, such as China, Malaysia, Thailand, Vietnam, and the Philippines, have also used the Sembung plant as a traditional medicine [7]. Species from the genus Blumea are distributed across tropical Asia, Africa, and Oceania [8], with the highest level of diversity in tropical Asia $[9,10]$, including Indonesia. To date, as many as 49 species of Blumea are distributed worldwide, with 27 found in Southeast Asia [11]. In the last decade, researchers have focused their investigations on species from the genus Blumea that are used in Ayurvedic (Indian) medicinal ingredients and traditional drinks (Loloh) by Balinese people in Indonesia [12,13].

Therefore, this review provides evidence-based information on the potential biological activity of B. balsamifera, not only toward a central role as a nutraceutical in traditional medicine but also as an interesting plant to undergo further phytochemical and pharmacological studies.

\section{Traditional Use in Several Countries}

B. balsamifera is a wild terrestrial plant that can grow to an altitude of 2200-3500 $\mathrm{m}$ asl in humid to dry areas (Figure-1) [14]. B. balsamifera has many names in several countries such as Ainaxiang and Dafeng "ai" in China, and it is commonly used 


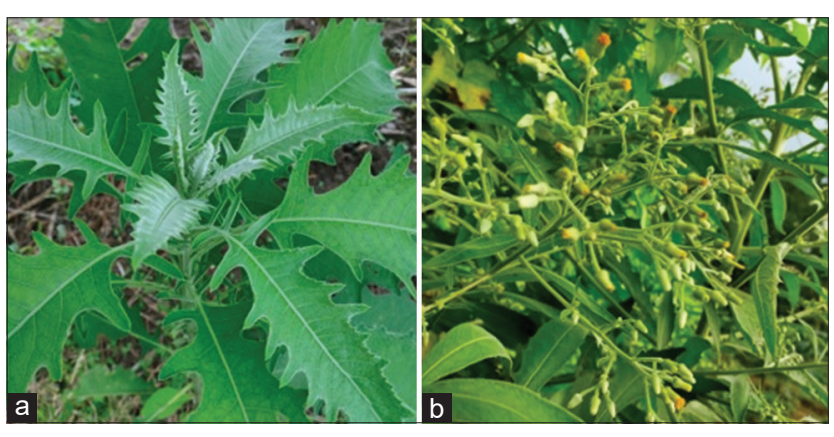

Figure-1: Sembung plants (Blumea balsamifera). (a) Leaves and (b) Flowers.

as an incense because of its high content in essential oil [15]. In Thailand, dried leaves of the Sembung (Naat) plant can be used as a cigarette to relieve sinusitis, colic pain, and cough and can be combined with other plants as a bath ingredient for women after giving birth [16]. In addition, Thai population also believes that Sembung "drives away spirits." In the Philippines, people are more familiar with the name Sambong, used as a traditional medicine for patients with kidney stones, common cold or as a diuretic [17]. Other Asian countries such as Malaysia and India also use Sembung as an Ayurvedic medicine $[18,19]$.

The use of the Sembung plant in traditional medicine in Indonesia is also known to be very diverse. Within Indonesia, this plant is known by different local names: Sembung utan (Sundanese), Sembung gantung, kuwuk, mingsa, langu (Java), Kamadhin (Madura), Sembung (Bali), Capo (Sumatra), and Afoat, Ampampau, and Madikapu (Eastern Indonesia) [20]. The Sembung plant can be used as a traditional drink by Balinese people called "Loloh Sembung" [21]. Loloh Sembung is made by boiling and brewing fresh and dried leaves [13].

\section{Progress on Phytochemical Studies Using B. balsamifera}

Studies show that more than 100 phytochemical constituents of $B$. balsamifera can be both volatile and non-volatile. The volatile constituent compounds consist of terpenoids, fatty acids, phenols, alcohols, aldehydes, ether, ketones, pyridine, furans, and alkanes. Flavonoids, flavanones, and chalcones are non-volatile constituents [7]. The diversity of the constituents found in $B$. balsamifera has potential medicinal benefits, as shown in Table-1 [22-54].

\section{Polyphenolic Compounds}

The leaf extract of $B$. balsamifera was reported to contain 18 polyphenol compounds, including 17 flavonoids and one phenyl ethanone, after analysis using high-performance liquid chromatography (HPLC) [55]. In addition, the flavonoid contents of this plant demonstrated antityrosinase and anticancer activities $[56,57]$.

\section{Fatty Acids}

Sembung leaves contain several fatty acids, as previously reported by Pang [7], including (11Z)-11hexadecenoic acid, trans-2-undercenoic acid, 9-hexadecenoic acid, capric acid, and palmitic acid [58,59].

\section{Terpenoid Compounds}

The essential oil obtained from $B$. balsamifera leaves was reported to have the following terpenoids: 1,8-cineole $(20.98 \%)$, borneol $(11.99 \%)$, $\beta$-caryophyllene $(10.38 \%)$, camphor $(8.06 \%)$, 4-terpineol (6.49\%), $\alpha$-terpineol (5.91\%), and caryophyllene oxide $(5.35 \%)$. These compounds are widely used as fumigants or volatile agents to kill insect pests, nematodes, and other pests [60].

\section{Flavonoids}

Several studies reported that Sembung is rich in flavonoids such as 3,4,5-trihydroxy-3,7 dimethoxyflavonones, 3,4,5-trihydroxy-7-ethoxyflavanone, and the new biflavonoid, 3,-O-7-biluteolin, isolated using a Soxhlet extraction method [61]. A total of 27 compounds were identified using ultra-HPLC, including 16 flavonoid aglucagons, five flavonoid glycosides, five chlorogenic acid analogs, and one coumarin [22].

\section{Progress on Pharmacological Studies of B. balsamifera}

Various experimental studies both in vitro and in vivo have reported the pharmacological activities of $B$. balsamifera, such as antioxidant, cytotoxic, antimicrobial, antifungal, anti-inflammatory, and hypolipidemic. Table-2 [13,22,56,62-80] summarizes some studies on the pharmacological activity of B. balsamifera.

\section{Antioxidant Activity}

B. balsamifera extract has demonstrated high antioxidant activity. Fresh and dry leaf extracts from $B$. balsamifera have been used as a traditional drink by Balinese people in Indonesia called Loloh. It was reported that dried leaves of $B$. balsamifera, obtained by brewing, had a tannin content of $13.15 \pm 0.11 \mathrm{mg}$ GAE/g, while boiled dried leaves showed a high antioxidant capacity of $5.55 \pm 0.01 \mathrm{mg} \mathrm{GAE} / \mathrm{g}$ [13]. Apart from B. balsamifera, other species such as Blumea lanceolaria were also reported to have good health benefits. The antioxidant activity of the methanol extract of $B$. lanceolaria leaves was assessed through three different methods 2,2-diphenylpicrylhydrazyl, ferric reducing antioxidant power test, and total phenolic content test, showing an antioxidant activity of $302.37 \pm 59.78 \mathrm{mg} / 100 \mathrm{~g}, 4.60 \pm 0.17 \mathrm{mg} / 100 \mathrm{~g}$, and $1298.93 \mathrm{mg} / 100 \mathrm{~g}$ [81], respectively.

Essential oils obtained from $B$. balsamifera have been widely used in various countries, especially in tropical Asia. Parts of the $B$. balsamifera plant were also reported to contain different essential oils. The 
Table-1: The diversity of constituents, molecular formulas, and bioactivity.

\begin{tabular}{|c|c|c|c|}
\hline \multicolumn{4}{|c|}{ Volatile constituents } \\
\hline Class & Molecular formula* & Bioactivity and medical benefit & Reference \\
\hline Terpenoids & $\mathrm{C} 5 \mathrm{H} 8$ & $\begin{array}{l}\text { Inhibition of NO production induced by LPS in } \\
\text { RAW264.7 macrophages }\end{array}$ & [24] \\
\hline Fatty acid & $\begin{array}{l}\mathrm{CH}_{3}\left(\mathrm{CH}_{2}\right)_{n} \mathrm{COOH} \\
\text { (with } \mathrm{n} \text { variation) }\end{array}$ & $\begin{array}{l}\text { Fatty acids, especially unsaturated fatty acids with } \\
\mathrm{n}-3 \text { and } \mathrm{n}-6 \text { have good bioactive and nutritional } \\
\text { compounds and play an important role in lipid } \\
\text { homeostasis and cardiovascular disease prevention, } \\
\text { prevention of chronic disease, anti-inflammatory }\end{array}$ & {$[25-28]$} \\
\hline Phenol & $\mathrm{C}_{6} \mathrm{H}_{6} \mathrm{O}$ or $\mathrm{C}_{6} \mathrm{H}_{5} \mathrm{OH}$ & $\begin{array}{l}\text { Has antibacterial activity against } S \text {. aureus and } \\
\text { high antioxidant activity, procoagulants }\end{array}$ & {$[23,29]$} \\
\hline Alcohol & $\mathrm{CH}_{3} \mathrm{CH}_{2} \mathrm{OH}$ or $\mathrm{C}_{2} \mathrm{H}_{6} \mathrm{O}$ & Has good antibacterial activity & {$[30]$} \\
\hline Aldehydes & $\mathrm{RCHO}$ & Anticancer and anti- inflammatory & {$[31,32]$} \\
\hline Ether & $\mathrm{C}_{4} \mathrm{H}_{10} \mathrm{O}$ or $\left(\mathrm{C}_{2} \mathrm{H}_{5}\right)_{2} \mathrm{O}$ or $\mathrm{CH}_{3} \mathrm{CH}_{2} \mathrm{OCH}_{2} \mathrm{CH}_{3}$ & As a natural anesthetic agent & [33] \\
\hline Ketones & $\mathrm{CH}_{3} \mathrm{COCH}_{3}$ & Anticancer, antimicrobial, and antioxidant activity & [34-36] \\
\hline Pyridine & $\mathrm{C}_{5} \mathrm{H}_{5} \mathrm{~N}$ & $\begin{array}{l}\text { Anticancer and phosphodiesterase- } 3 \text { inhibitors, } \\
\text { antibacterial activity, especially against } \\
\text { methicillin-resistant } S \text {. aureus, antiepileptic, } \\
\text { anticonvulsant agent }\end{array}$ & {$[37-40]$} \\
\hline Furan & $\mathrm{C}_{4} \mathrm{H}_{4} \mathrm{O}$ & $\begin{array}{l}\text { Has anticancer potential in three human cancer } \\
\text { cell lines, such as breast cancer cells (MCF-7), } \\
\text { lung cancer cells (A549), and melanoma cancer } \\
\text { cells (A-375). Has good antibacterial activity on } \\
\text { Streptococcus pyogenes, Proteus vulgaris, and } \\
\text { Escherichia coli. Has antidiabetic activity }\end{array}$ & {$[41-43]$} \\
\hline Alkanes & $\begin{array}{l}\mathrm{C}_{n} \mathrm{H}_{2 n+2} \text { (straight and branched chain } \\
\text { alkanes) } \\
\mathrm{C}_{n} \mathrm{H}_{2 n} \text { (cyclic alkanes) }\end{array}$ & $\begin{array}{l}\text { Anticancer activity of pulmonary carcinoma } \\
\text { cells (A549), and antibacterial and cytotoxic. }\end{array}$ & {$[44,45]$} \\
\hline \multicolumn{4}{|c|}{ Non-volatile constituents } \\
\hline Class & Molecular formula* & Bioactivity and medical benefit & Reference \\
\hline $\begin{array}{l}\text { Flavones } \\
\text { (Family of } \\
\text { flavonoids) }\end{array}$ & $\mathrm{C}_{15} \mathrm{H}_{10} \mathrm{O}_{2}$ & Antioxidant activity and anti-tyrosinase activity & [46] \\
\hline $\begin{array}{l}\text { Flavonols } \\
\text { (Family of } \\
\text { flavonoids) }\end{array}$ & $\mathrm{C}_{15} \mathrm{HO}_{3} \mathrm{R}_{9}$ & Wound healing and anti-inflammatory activity & {$[22]$} \\
\hline $\begin{array}{l}\text { Flavonoid or } \\
\text { bioflavonoid }\end{array}$ & $\mathrm{C}_{6}-\mathrm{C}_{3}-\mathrm{C}_{6}$ & $\begin{array}{l}\text { Treat kidney disorders, hypertension, wounds, } \\
\text { diarrhea, rheumatism, shortness of breath, colds } \\
\text { and coughs, respiratory tract infections, stomach } \\
\text { pain and treat urinary tract infections }\end{array}$ & [47] \\
\hline $\begin{array}{l}\text { Two new } \\
\text { flavonoids }\end{array}$ & $\begin{array}{l}\text { 1) } \mathrm{C}_{18} \mathrm{H}_{16} \mathrm{O}_{8} \\
\text { 2) } \mathrm{C}_{20} \mathrm{H}_{20} \mathrm{O}_{8}\end{array}$ & $\begin{array}{l}\text { Antiproliferative cancer cells, especially flavonoids } \\
\text { compounds 1) } 3,3^{\prime}, 4^{\prime} \text {-Trihydroxy- } 6,7 \text {, } \\
8 \text {-trimethoxy flavone, versus compounds of } \\
\text { 2) 3-Hydroxy-6,7,8,3',4'-pentamethoxy flavone. }\end{array}$ & {$[48]$} \\
\hline Flavonoids & $\mathrm{C}_{6}-\mathrm{C}_{3}-\mathrm{C}_{6}$ & $\begin{array}{l}\text { Inhibition of xanthine oxidase }(\mathrm{XO}) \text { and } \\
\text { enzymatically is able to produce anti-free radicals }\end{array}$ & [49] \\
\hline Chalcone & $\mathrm{C}_{15} \mathrm{H}_{12} \mathrm{O}$ & $\begin{array}{l}\text { Anticancer, antibacterial, activity, cardiovascular } \\
\text { infections, and antiparasitic. }\end{array}$ & {$[50-54]$} \\
\hline
\end{tabular}

*Source: pubchem.ncbi.nlm.nih.gov/compound. (National Library of Medicine). NO=Nitric oxide

highest yield of essential oil, $0.65 \mathrm{~mL} / 100 \mathrm{~g}$, was obtained from young leaves. In addition, shoots and young leaves also showed the strongest antioxidant activity. Dimethoxydurene, $\beta$-caryophyllene, and $\alpha$-caryophyllene, which played an important role in the plant's antioxidant activity, have the potential to be developed as ingredients in the cosmetic and medicinal industries [58].

\section{Antimicrobial Activity}

B. balsamifera leaves have been used in the treatment of bacterial infections. The essential oil, and $n$-hexane, dichloromethane, and methanol extracts of $B$. balsamifera have been evaluated for their antibacterial activity using agar diffusion and microdilution methods. The essential oil gave the best results with a minimum inhibition concentration (MIC) value of $150 \mu \mathrm{g} / \mathrm{mL}$ against Bacillus cereus and a MIC of $1.2 \mathrm{mg} / \mathrm{mL}$ against Staphylococcus aureus. Besides, the $n$-hexane extract also showed good bactericidal activity [62]. Compounds with high antioxidant activity, such as $\delta$-elements, $\alpha$-cubenene, caryophyllene, caryophyllene epoxide, $\gamma$-eudesmol, xanthoxylin, and $\alpha$-eudesmol, were identified from the essential oil of B. balsamifera [82].

The ethanol extract of the stems, roots, and leaves of $B$. lanceolaria also showed good antimicrobial activity against $S$. aureus, namely, $10-12 \mathrm{~mm}$, when 


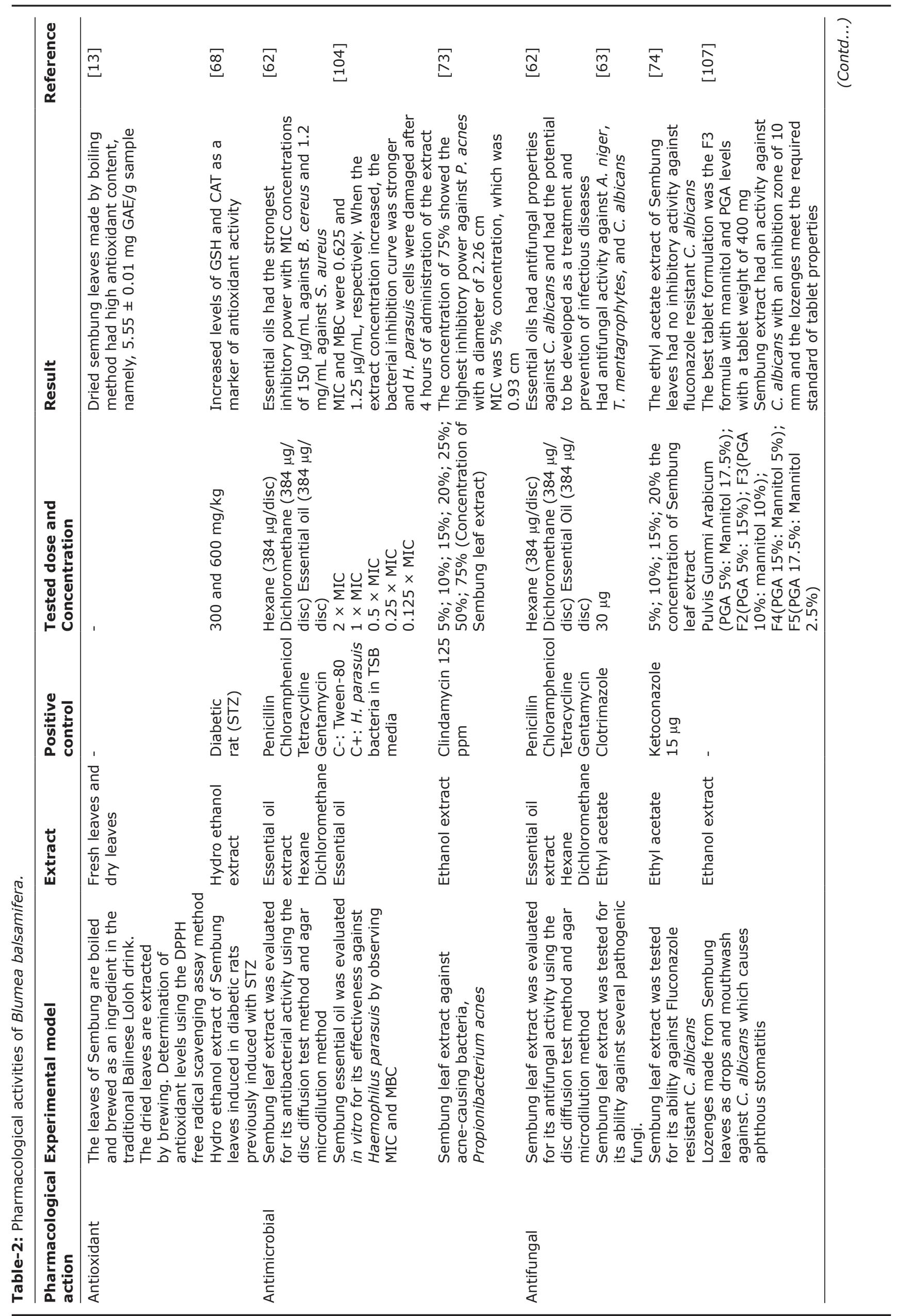




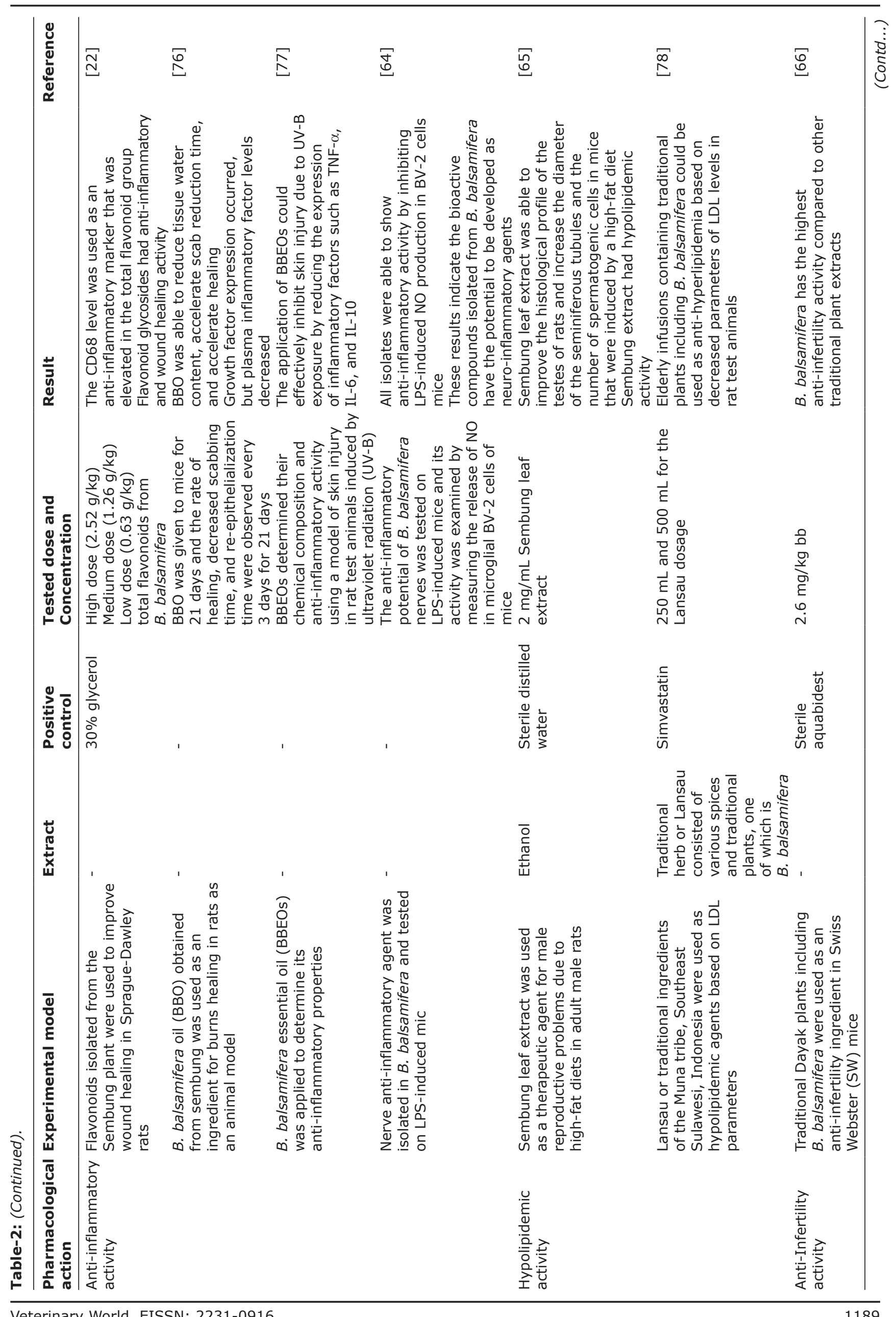

Veterinary World, EISSN: 2231-0916 


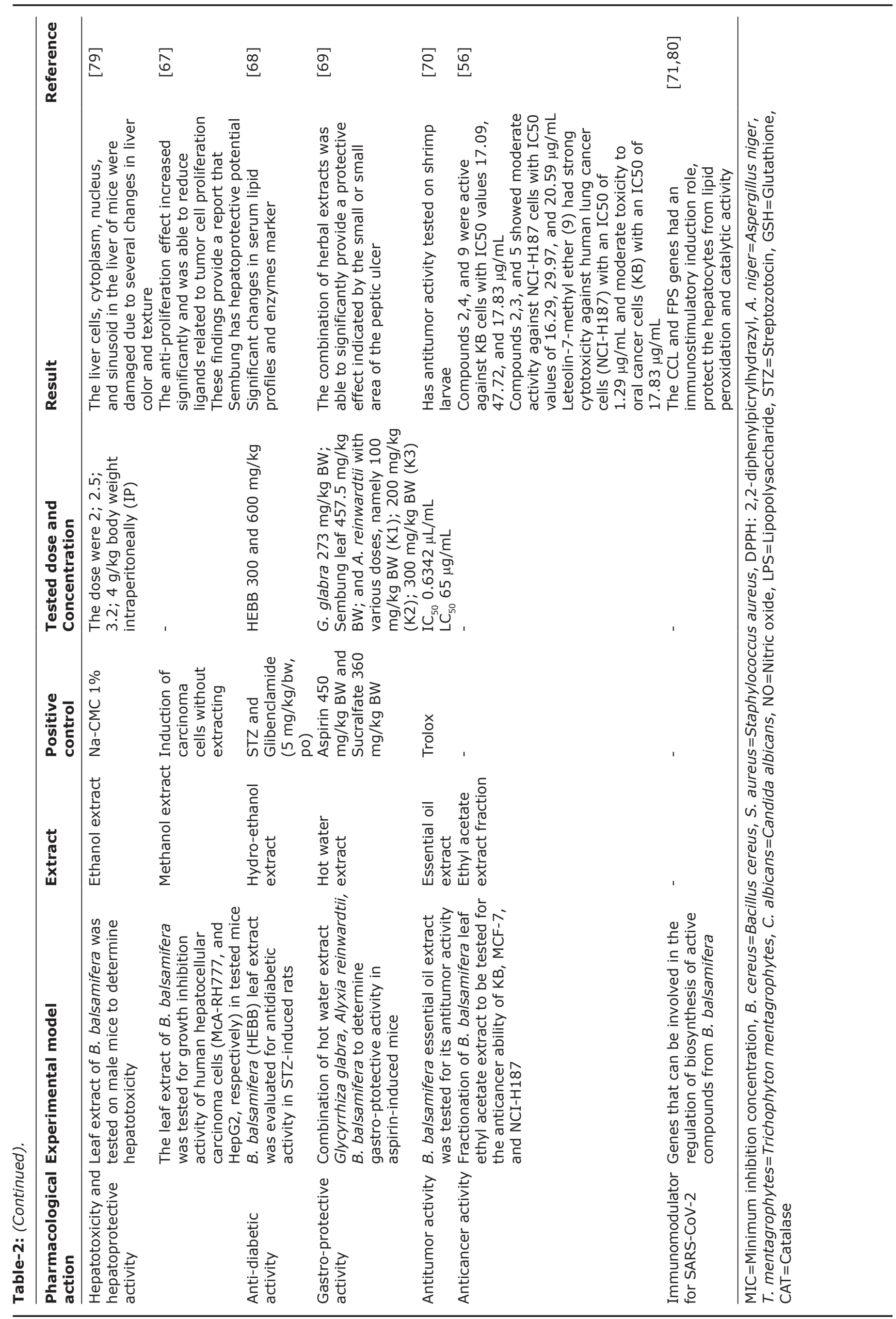


compared with standard antibiotics, 2-10 $\mathrm{mm}$ [23]. Blumea lacera leaf extract, for example, was reported to have antimicrobial activity [83].

\section{Antifungal Activity}

Antifungal activity had also been reported in $B$. balsamifera extract. Antifungal activity tests have been carried out on Aspergillus niger, Trichophyton mentagrophytes, and Candida albicans. Compounds with antifungal activity in Sembung leaves include icthyothereol acetate and cryptomeridiol [63]. The antifungal role of B. lacera was studied against Aspergillus flavus, A. niger, Alternaria sp., Penicillium sp., and Fusarium sp. Almost all extracts from both methanol, acetone, and water extracts were reported to have antifungal activity, when compared to standard carbendazim [84].

\section{Anti-inflammatory Activity}

Scientific evidence has demonstrated B. balsamifera anti-inflammatory activity. When the wound healing process occurs, it will go through several stages such as inflammatory response, migration, proliferation, and regeneration of new tissue [85]. Total flavonoids isolated from $B$. balsamifera were used as a skin wound healing agent in Sprague-Dawley rats. The healing activity was determined by measuring CD68 levels, vascular endothelial growth factor, transformation growth factor- $\beta 1$, and hydroxyproline. The results of that study indicated that flavonoids were key in the successful wound healing process, increasing the expression of growth factors [22].

The study of the anti-inflammatory process was also carried out using Blumea aurita. B. aurita had the highest percentage of inhibition of edema $(\mathrm{EI} \%=53 \%)$ after $4 \mathrm{~h}$ of oral administration of the extract at a dose of $400 \mathrm{mg} / \mathrm{kg}$, followed by $6 \mathrm{~h}(\mathrm{EI} \%=67 \%)$ at a dose of $800 \mathrm{mg} / \mathrm{kg}$, with albino Wistar mice [86]. The aqueous extract of Blumea mollis was also used in an acute and chronic anti-inflammatory therapy on carrageenan-induced rat leg edema [87].

In addition, $B$. balsamifera extract was also reported to have anti-inflammatory neuroprotective activity by reducing nitric oxide in lipopolysaccharide-induced rat microglial BV-2 cells. This inhibition may have occurred due to the interaction of the bioactive compounds of $B$. balsamifera extract with iNOS protein [64]

\section{Hypolipidemic Activity}

Hypolipidemic drug agents lower lipoprotein concentrations, transporting excess cholesterol, and triglycerides in the blood [88]. The antihyperlipidemic nature or potential in plants is important in reducing atherosclerosis [89]. The Sembung plant has been used as an antihyperlipidemic agent in vitro in 3-4 months old adult male Wistar rats (Rattus norvegicus) with induced high-fat feed. The Sembung extract had anti-hyperlipidemic activity by increasing spermatocytes [65]. A traditional drink from Southeast
Sulawesi, Indonesia, "Lansau," made from 44 traditional ingredients (including Sembung) showed that Lansau's ethanol extract was antihyperlipidemic, reducing fat degeneration and being able to repair cell damage at a dose of $27,628 \mathrm{mg} / \mathrm{kg}[90]$.

\section{Anti-infertility Activity}

Infertility can be defined as a medical condition that can cause psychological and physical harm. Several factors such as age, tubal factors in women, obesity, significant reduction in semen parameters, cigarette consumption, and excessive alcohol consumption in men could trigger infertility [91]. Ethnopharmacological surveys on uses of traditional medicines against infertility have been widely completed around the world [92].

Local plant extracts from the Dayak tribe, Kalimantan, Indonesia, such as $B$. balsamifera, Croton tiglium, Metroxylon sagu, and Fagraea racemosa Jack, have been used as anti-infertility substances in vitro. All extracts were able to inhibit the estrous and metestrus cycles. A decrease in the corpus luteum and fetus was attributed to the anti-infertility effect of the extract against the inhibition of folliculogenesis. Researchers also reported that $B$. balsamifera extract had promising anti-infertility activity compared to other plant extracts used in this study [66].

\section{Hepatoprotective Activity}

The incidence of liver diseases affects millions of people worldwide. The prevalence of liver cirrhosis from autopsy studies ranges globally from $4.5 \%$ to $9.5 \%$ of the global population [93,94], with more than 50 million people worldwide (adult population) potentially affected by chronic liver disease [95].

A phytotherapy approach in the development of modern medicines is still very much needed [96]. The benefits of the phytochemical compounds in $\mathrm{B}$. balsamifera have been widely used to improve physiological disorders and other degenerative diseases. Researchers also mentioned that the methanol extract of $B$. balsamifera (BME) induced growth and developmental inhibition of human hepatocellular carcinoma cells (McA-RH7777 and HepG2, respectively) in mice. These results were confirmed by the antiproliferative effect of BME, which increased slightly but significantly reduced the level of proliferation-related ligand (APRIL) stimulating tumor cells [67].

The hepatoprotective effect was also reported for the ethanol extract of $B$. lacera, which showed minimal damage to liver structures, decreased aspartate aminotransferase, Alkaline phosphatase, and bilirubin in ethanol-induced rats [97].

\section{Antidiabetic Activity}

The use of $B$. balsamifera as an antidiabetic in traditional medicine has been widely used, especially in Ayurvedic medicine in India. The administration of a hydro-ethanolic extract from $B$. balsamifera 
(HEBB) at doses of 300 and $600 \mathrm{mg} / \mathrm{kg}$, in streptozotocin (STZ)-induced diabetic rats, showed a decrease in blood glucose, lipid profile, serum marker enzymes, and levels of glutathione and catalase, when compared with the diabetes control group [68].

Other species such as B. lacera D.C (Asteraceae) was also reported to have antidiabetes benefits. Methanol extract $B$. lanceolaria (MEBL) and water extract $B$. lanceolaria were tested on hyperglycemic rats induced by STZ. Treatment with MEBL at doses of 200 and $400 \mathrm{mg} / \mathrm{kg}$ BW was able to lower blood glucose levels, increasing glycated hemoglobin, restoring lipid levels, rejuvenating pancreatic beta cells, and increasing the level of insulin secretion in the blood [98].

\section{Gastroprotective Activity}

Digestive disorders such as peptic ulcers are caused by an imbalance of aggressive factors (gastric acid and pepsin) and defense factors (mucosal secretion, bicarbonate secretion, and to mucosal epithelial regeneration) [69]. Some traditional plants, such as Sembung can be used as a medicinal ingredient for gastrointestinal disorders. Experimentally, the gastroprotective effect of herbal ingredients was applied to mice in a model of aspirin-induced gastric ulcers. This study confirmed that the herbal extract formulation using Sembung was able to provide a gastroprotective effect, with the lowest eosinophil and mast cells count $[69,99]$.

\section{Antitumor Activity}

The essential oil extract of $B$. balsamifera was reported to have 42 types of chemical components, which were tested for their antitumor activity using the method of shrimp-larvae mortality determination, which is a simple, convenient, and inexpensive method of determining internal biological activity initiated by Jiang et al. [70]. This method has been widely used in determining the toxic components and contaminants in food, as well as the determination of biological activity [100]. The method was carried out using 25-30 larvae in each group. Treatment was given when shrimp eggs hatched (1\% DMSO was added to dissolve the sample). The survival rate was observed for $24 \mathrm{~h}$ at room temperature. The treatment at $65 \mu \mathrm{g} \mathrm{mL}$ showed strong cytotoxicity to shrimp larvae. In conclusion, this extract was set as potential for further studies on antitumor activity [70].

\section{Anticancer Activity}

Cancer is a potentially life-threatening disease with more than 100 different types already occurring due to molecular changes in cells [101]. Cancer is also reported to be the third leading cause of death worldwide after cardiovascular and infectious diseases [102]. Medicinal plants have been reported as potential cancer treatment agents, as about $50 \%$ of compounds derived from medicinal plants demonstrate anticancer activity [103].
A study reported the anticancer activity of the BME on mice induced by human hepatocellular carcinoma cells (McA-RH7777 and HepG2, respectively). BME was able to reduce the level of APRIL, which is able to stimulate tumor cells. APRIL is a new member of the tumor necrosis factor, which is reported to stimulate tumor cell growth, modulate tumor cell apoptosis, and regulate humoral immunity $[104,105]$.

The anticancer potential of other species such as Blumea eriantha was also tested in vitro using the microtetrazolium assay (MTT) test on cervical cancer cell (HeLa) and B16F10 cell gallus. The expressions of the p53 and $\mathrm{Bcl}-2$ genes associated with apoptosis were also determined. The results showed that the methanol extract of $B$. eriantha induced strong antioxidant and anticancer properties. In addition, this extract was also to prevent cancer cell metastasis [106].

\section{Immunomodulator Activity for Severe Acute Respiratory Syndrome-Coronavirus (SARS-CoV-2) in CoV Disease (COVID)-19}

Novel COVID-2019, related with SARS, has been declared as a global pandemic causing deaths in 216 countries worldwide [107]. Until now, no vaccine or special treatment for SARS-CoV-2 has been available despite the extraordinary recent research efforts [108]. The use of drugs such as remdesivir, lopinavir/ritonavir, and hydroxychloroquine has been widely claimed to reduce the symptoms of COVID19. To date, 200 clinical trials have been registered on the clinicaltrials.gov site. However, the expediency of drugs being studied is still unclear [109].

Therefore, the use of traditional medicinal plants is recommended by some for management or increasing the immune status of patients with COVID-19. A report showed that $90 \%$ of traditional medicines resulted in $90 \%$ recovery in 214 patients treated for COVID-19 [110]. The use of traditional medicine also claimed to be able to prevent COVID-19 infection in healthy people and to increase the immunity of patients with mild or severe COVID-19 symptoms [110]. In Indonesia, the use of "Empon-empon" (In Java) or Loloh (Balinese) made from traditional medicinal plants is also believed to have a role in modulating the immune system in COVID-19 patients [71].

Therapeutic agents against COVID-19 can be divided into several categories based on specific pathways: (1) Preventing the synthesis and replication of viral RNA, (2) blocking the virus in order not to bind to human cell receptors or by inhibiting the assembly process of viral genetic material, (3) restoring the innate immunity of the host, and (4) acting on specific receptors or enzymes so that the virus does not enter the host cell. Until now, there is still no specific scientific data mentioning $B$. balsamifera as an antiviral agent for COVID-19. Therefore, we suggest that the antiviral potential of its phytocomponents could be tested through computational studies (in silico studies), in vitro, and in vivo. Figure-2 summarizes the 


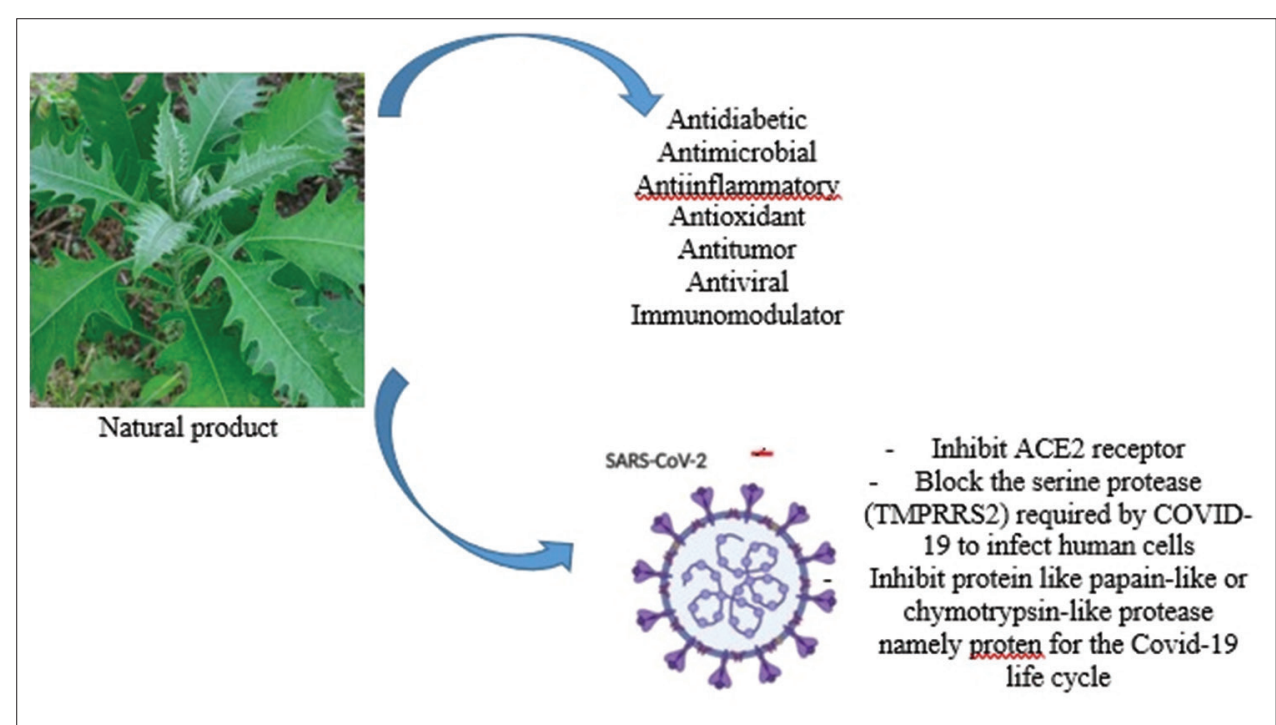

Figure-2: Summary of the potential of natural products from the Sembung plant (Blumea balsamifera).

potency of $B$. balsamifera as a medicinal agent and possible anti-SARS-CoV-2.

\section{Future Prospective}

More exploration and research have been carried out to verify the benefits of B. balsamifera, which is widely used against various diseases by people in several countries. The diversity of its constituents, molecular structure, bioactivity, and pharmacological studies has been extensively described in this review. Researchers have also demonstrated the efficacy of this plant in treating diseases (Table-2). However, further and more detailed studies should be carried out to assess the use of this plant in a number of other experimental animals such as Ferret (Mustela putorius) [111], or Zebrafish (Danio rerio) as well as on human subjects (can be considered) [112]. It has been reported that the leaves of $B$. balsamifera are the most widely used part in extracts (water, methanol, and ethanol) in studies against cancer, diabetes, hyperlipidemia, infertility, and infectious diseases. Its biological activity is still not fully proven, so other clinical studies would be needed [3].

Some other species of this family have been the focus of some research. $B$. lacera was reported to be antidiabetic, antifungal, and hepatoprotective; $B$. eriantha was able to demonstrate its anticancer activity. Therefore, research should focus in the identification and isolation of bioactive compounds according to the known pharmacological activity of $B$. balsamifera. Especially during the COVID-19 pandemic, authentic Indonesian herbal ingredients are needed to assess their benefits in modulating the immune system.

\section{Conclusion}

The Sembung plant (B. balsamifera) has proven to possess important biological activities with additional potential to be developed as a candidate for future essay-based isolation and identification of its bioactive.

\section{Authors' Contributions}

IGW designed and prepared the manuscript. IMJ made a critical comment in this manuscript. Both authors read and approved the final manuscript.

\section{Acknowledgments}

The author would like to thank the Ministry of Research, Technology and Higher Education of the Republic of Indonesia (KEMENRISTEKDIKTI) for supporting the study with the Domestic Postgraduate Education Scholarship (BPPDN) with Decision Letter Number: B/276/D3.2/KD.02.00/2019 and Dhyana Pura University, Bali. Thanks to Putu Angga Wiradana, who helped in editing, preparing, and revision of the manuscript.

\section{Competing Interests} interests.

The authors declare that they have no competing

\section{Publisher's Note}

Veterinary World remains neutral with regard to jurisdictional claims in published institutional affiliation.

\section{References}

1. Ansori, A.N.M., Fadholly, A., Hayaza, S., Susilo, R.J.K., Inayatillah, B., Winarni, D. and Husen, S.A. (2020) A Review on medicinal properties of mangosteen (Garcinia mangostana L.). Res. J. Pharm. Technol., 13(2): 974.

2. Peltzer, K. and Pengpid, S. (2015) Utilization and practice of traditional/complementary/alternative medicine (T/CAM) in Southeast Asian Nations (ASEAN) member states. Stud. Ethnomed., 9(2): 209-218.

3. Wannes, W.A. and Tounsi, M.S. (2020) Phytochemical composition and health properties of Lycium europaeum L.: A review. Acta Ecol. Sin., 2(10): 1-12.

4. Wannes, W.A., Tounsi, M.S. and Marzouk, B. (2018) A review of Tunisian medicinal plants with anticancer activity. J. Complement. Integr. Med., 15(1): 52.

5. Wink, M. (2008) Evolutionary advantage and molecular modes of action of multi-component mixtures used in phytomedicine. Curr. Drug Metab., 9(10): 996-1009. 
6. Wink, M. (2015) Modes of action of herbal medicines and plant secondary metabolites. Medicines, 2(3): 251-286.

7. Pang, Y., Wang, D., Fan, Z., Chen, X., Yu, F., Hu, X., Wang, K. and Yuan, L. (2014) Blumea balsamifera a phytochemical and pharmacological review. Molecules, 19(7): 9453-9477.

8. Peng, Y., Yang, C. and Luo, Y. (2020) Blumea htamanthii (Asteraceae), a new species from Myanmar. PhytoKeys, 138: 225-232.

9. Pornpongrungrueng, P., Borchsenius, F., Englund, M., Anderberg, A.A. and Gustafsson, M.H.G. (2007) Phylogenetic relationships in Blumea (Asteraceae: Inuleae) as evidenced by molecular and morphological data. Plant Syst. Evol., 269(3-4): 223-243.

10. Pornpongrungrueng, P., Borchsenius, F. and Gustafsson, M.H.G. (2009) Relationships within Blumea (Inuleae, Asteraceae) and the utility of the 5SNTS in specieslevel phylogeny reconstruction. Taxon, 58(4): 1181-1193.

11. Pornpongrungrueng, P., Gustafsson, M.H.G., Borchsenius, F., Koyama, H. and Chantaranothai, P. (2016) Blumea (Compositae: Inuleae) in continental Southeast Asia. Kew Bull., 71(1): 1.

12. Kim, J.S. and Kang, S.S. (2013) Chemical constituents of plants from the genus Patrinia. Nat. Prod. Sci., 19(2): 77-119.

13. Kusumawati, I. and Yogeswara, I. (2016) Antioxidant and antibacterial capacity of Loloh Sembung (Blumea balsamifera) based on extraction method. Maj. Obat Tradis., 21(3): 143-148.

14. Rahardjo, S.S. (2016) Review tanaman sembung [Blumea balsamifera (L.)]. Proc. Mulawarman Pharm. Conf., 3(1): 18-28.

15. Chen, M. (2019) Studies on the Active Constituents of Blumea balsamifera. Shanghai Jiao Tong University, Shanghai, China.

16. Ruangrungsi, N., Tantivatana, P., Tappayuthpijarn, P., Borris, R.P. and Cordell, G.C. (1985) Traditional medicinal plants of Thailand VI. isolation of cryptomeridiol from Blumea balsamifera. ScienceAsia, 11(1): 047.

17. Montealegre, C.M. and De Leon, R.L. (2016) Blumea balsamifera (Sambong) tea as a therapeutic drink for calcium oxalate stones. MATEC Web Conf., 62(02002): 4.

18. Tomar, A. and Tomar, C.A. (2017) Folk medicinal use of Blumea lacera (BURM. F.) DC. To cure threadworms. J. Med. Plants Stud., 5(2): 336-337.

19. Zaki, P.H., Gandaseca, S., Rashidi, N.M. and Ismail, M.H. (2019) Traditional usage of medicinal plants by Temiar tribes in the State of Kelantan, Peninsular Malaysia. For. Soc., 3(2): 227-234.

20. Nursamsu, N. and Firmansyah, F. (2017) Utilization of Sembung (Blumea balsamifera) leaves as traditional medicine in the Javanese village of the youth vocational sub-district of Aceh Tamiang district in 2015.

21. Sõukand, R., Quave, C.L., Pieroni, A., Pardo-deSantayana, M., Tardío, J., Kalle, R., Łuczaj, L., Svanberg, I., Kolosova, V., Aceituno-Mata, L., Menendez-Baceta, G., Kołodziejska-Degórska, I., Pirożnikow, E., Petkevičius, R., Hajdari, A. and Mustafa, B. (2013) Plants used for making recreational tea in Europe: A review based on specific research sites. J. Ethnobiol. Ethnomed., 9(1): 58.

22. Pang, Y., Zhang, Y., Huang, L., Xu, L., Wang, K., Wang, D., Guan, L., Zhang, Y., Yu, F., Chen, Z. and Xie, X. (2017) Effects and mechanisms of total flavonoids from Blumea balsamifera (L.) DC. on skin wound in rats. Int. J. Mol. Sci., 18(12): 2766.

23. Vineet, K.M., Ajit, K.P., Vanlalhmangaihi, K., Nachimuthu, S.K. and Bhim, P.S. (2015) Antimicrobial and antioxidant activities of Blumea lanceolaria (Roxb.). J. Med. Plants Res., 9(4): 84-90.

24. Chen, M., Qin, J.J., Fu, J.J., Hu, X.J., Liu, X.H., Zhang, W.D. and Jin, H.Z. (2010) Blumeaenes A-J, sesquiterpenoid esters from Blumea balsamifera with NO inhibitory activity. Planta Med., 76(9): 897-902.
25. Rajaram, S. (2014) Health benefits of plant-derived $\alpha$-linolenic acid. Am. J. Clin. Nutr., 100(Suppl 1): 443S-448S.

26. Vangaveti, V.N., Jansen, H., Kennedy, R.L. and Malabu, U.H. (2016) Hydroxyoctadecadienoic acids: Oxidised derivatives of linoleic acid and their role in inflammation associated with metabolic syndrome and cancer. Eur. J. Pharmacol., 15(785): 70-76.

27. López-Vicario, C., Rius, B., Alcaraz-Quiles, J., GarcíaAlonso, V., Lopategi, A., Titos, E. and Clària, J. (2016) Pro-resolving mediators produced from EPA and DHA: Overview of the pathways involved and their mechanisms in metabolic syndrome and related liver diseases. Eur. $J$. Pharmacol., 15(785): 133-143.

28. Calder, P.C. (2015) Marine omega-3 fatty acids and inflammatory processes: Effects, mechanisms and clinical relevance. Biochim. Biophys. Acta, 1851(4): 469-484.

29. Li, H., Cuiwu, L., Aiyuan, L., Baoyao, W., Jianwen, T. and Lue, L. (2010) Pro-coagulant activity of phenolic acids isolated from Blumea riparia. Nat. Prod. Commun., 5(8): 1263-1266.

30. Ongsakul, M., Jindarat, A. and Rojanaworarit, C. (2009) Antibacterial effect of crude alcoholic and aqueous extracts of six medicinal plants against Staphylococcus aureus and E. coli. Health (San Francisco), 23(3): 153-156.

31. Bębenek, E., Chrobak, E., Marciniec, K., KadelaTomanek, M., Trynda, J., Wietrzyk, J. and Boryczka, S. (2019) Biological activity and in silico study of 3-modified derivatives of betulin and betulinic aldehyde. Int. J. Mol. Sci., 20(6): 1372.

32. Joshi, H., Singh, B.K., Saxena, G., Singh, V., Singh, R.P. and Arya, E. (2014) Novel halogens substituted coumarin-aldehyde as an anti-inflammatory agent. World $J$. Pharm. Pharm. Sci., 2(3): 1-15.

33. Chang, C.Y., Goldstein, E., Agarwal, N. and Swan, K.G. (2015) Ether in the developing world: Rethinking an abandoned agent. BMC Anesthesiol., 15(1): 149.

34. Poff, A.M., Ari, C., Arnold, P., Seyfried, T.N. and D'Agostino, D.P. (2014) Ketone supplementation decreases tumor cell viability and prolongs survival of mice with metastatic cancer. Int. J. Cancer, 135(7): 1711-1720.

35. Kawase, M., Motohashi, N., Sakagami, H., Kanamoto, T., Nakashima, H., Ferenczy, L., Wolfard, K., Miskolci, C. and Molnár, J. (2001) Antimicrobial activity of trifluoromethyl ketones and their synergism with promethazine. Int. J. Antimicrob. Agents, 18(2): 161-165.

36. Greco, T., Glenn, T.C., Hovda, D.A. and Prins, M.L. (2016) Ketogenic diet decreases oxidative stress and improves mitochondrial respiratory complex activity. J. Cereb. Blood Flow Metab., 36(9): 1603-1613.

37. Davari, A.S., Abnous, K., Mehri, S., Ghandadi, M. and Hadizadeh, F. (2014) Synthesis and biological evaluation of novel pyridine derivatives as potential anticancer agents and phosphodiesterase-3 inhibitors. Bioorg. Chem., 57(10): 83-89.

38. Reen, G.K., Kumar, A. and Sharma, P. (2017) In vitro and in silico evaluation of 2-(substituted phenyl) oxazolo[4,5-b] pyridine derivatives as potential antibacterial agents. Med. Chem. Res., 26(12): 3336-3344.

39. Ulloora, S., Adhikari, A.V. and Shabaraya, R. (2013) Synthesis and antiepileptic studies of new imidazo[1,2-a] pyridine derivatives. Chin. Chem. Lett., 24(9): 853-856.

40. Bhandari, S., Tripathi, A.C. and Saraf, S.K. (2013) Novel 2-pyrazoline derivatives as potential anticonvulsant agents. Med. Chem. Res., 22(11): 5290-5296.

41. Rao, G.P.C., Ramesh, V., Ramachandran, D. and Chakravarthy, A.K. (2019) Design, synthesis and anticancer evaluation of novel furan sulphonamide derivatives. Russ. J. Gen. Chem., 89(3): 486-491.

42. Malladi, S., Nadh, R.V., Babu, K.S. and Babu, P.S. (2017) Synthesis and antibacterial activity studies of 2,4-di substituted furan derivatives. Beni Suef Univ. J. Basic Appl. Sci., 6(4): 345-353.

43. Babu, S.P. and Babu, K.S. (2012) Synthesis and antidiabetic activity of 2, 4- disubstituted furan derivatives. Pharm. 
Chem., 4(6): 2178-2186.

44. Liang, Q., Linxia, X. and Rui, L. (2020) Convenient synthesis and biological evaluation of Bis (indolyl) methane alkaloid and Bis (aryl) alkanes derivatives with anticancer properties keywords. Beilstein Arch, 2020(1): 202060.

45. de Martins, C.M., do Nascimento, E.A., de Morais, S.A.L., de Oliveira, A., Chang, R., Cunha, L.C.S., Martins, M.M., Martins, C.H.G., da Moraes, T.S., Rodrigues, P.V., da Silva, C.V. and de Aquino, F.J.T. (2015) Chemical constituents and evaluation of antimicrobial and cytotoxic activities of Kielmeyera coriacea Mart. and Zucc. essential oils. Evid. Based Complement. Altern. Med., 2015: 842047.

46. Dao, V.Q., Thi, T., Giang, L., Cang, D.T., Nguyen, L., Linh, T., Thi Ben, T., Ai Uyen, N.P. and Suong, N.K. (2017) Antioxidant and antityrosinase activities of flavonoid from Blumea balsamifera (L.) DC. leaves. Eur. J. Res. Med. Sci., 5(1): 1-6.

47. Boy, H.I.A., Rutilla, A.J.H., Santos, K.A., Ty, A.M.T., Yu, A.I., Mahboob, T., Tangpong, J. and Nissapatorn, V. (2018) Recommended medicinal plants as source of natural products: A review. Digit. Chin. Med., 1(2): 131-142.

48. Tambewagh, U.U., Javir, G.R., Joshi, K.S. and Rojatkar, S.R. (2019) Two new polyoxygenated flavonoids from Blumea eriantha DC, methanol extract and their antiproliferative activity. Nat. Prod. Res., 3(10): 1-8.

49. Nessa, F., Ismail, Z. and Mohamed, N. (2010) Xanthine oxidase inhibitory activities of extracts and flavonoids of the leaves of Blumea balsamifera. Pharm. Biol., 48(12): 1405-1412.

50. Madhavi, S., Sreenivasulu, R., Yazala, J.P. and Raju, R.R. (2017) Synthesis of chalcone incorporated quinazoline derivatives as anticancer agents. Saudi Pharm. J., 25(2): 275-279.

51. Choudhary, A.L. and Juyal, V. (2011) Synthesis of chalcone and their derivatives as antimicrobial agents. Int. J. Pharm. Pharm. Sci., 3(3): 125-128.

52. Hsieh, C.T., Hsieh, T.J., El-Shazly, M., Chuang, D.W., Tsai, Y.H., Yen, C.T., Wu, S.F., Wu, Y.C. and Chang, F.R. (2012) Synthesis of chalcone derivatives as potential antidiabetic agents. Bioorg. Med. Chem. Lett., 22(12): 3912-3915.

53. Nurkenov, O.A., Ibraev, M.K., Schepetkin, I.A., Khlebnikov, A.I., Seilkhanov, T.M., Arinova, A.E. and Isabaeva, M.B. (2019) Synthesis, structure, and anti-inflammatory activity of functionally substituted chalcones and their derivatives. Russ. J. Gen. Chem., 89(7): 1360-1367.

54. Aljamali, N.M., Daylee, S.H. and Kadhium, A.J. (2020) Review on chemical-biological fields of chalcone compounds. Forefront J. Eng. Technol., 2(1): 33-44.

55. Tan, D., Yang, Z., Zhang, Q., Ling, H., Du, Y., Lu, Y., Xie, T., Zhou, X., Qin, L. and He, Y. (2020) Simultaneous quantitative determination of polyphenolic compounds in Blumea balsamifera (Ai-Na-Xiang, Sembung) by high-performance liquid chromatography with photodiode array detector. Int. J. Anal. Chem., 2020: 9731327.

56. Saewan, N., Koysomboon, S. and Chantrapromma, K. (2011) Anti-tyrosinase and anticancer activities of flavonoids from Blumea balsamifera DC. J. Med. Plants Res., 5(6): 1018-1025.

57. Fazilatun, N., Nornisah, M. and Zhari, I. (2005) Superoxide radical scavenging properties of extracts and flavonoids isolated from the leaves of Blumea balsamifera. Pharm. Biol., 43(1): 15-20.

58. Yuan, Y., Huang, M., Pang, Y.X., Yu, F.L., Chen, C., Liu, L.W., Chen, Z.X., Zhang, Y.B., Chen, X.L. and Hu, X. (2016) Variations in essential oil yield, composition, and antioxidant activity of different plant organs from Blumea balsamifera (L.) DC. at different growth times. Molecules, 21(8): 1024.

59. Aboaba, S. and Choudhary, I. (2015). Chemical Composition and Biological Activities of the Volatile Oils of Palisota hirsute (Thunb) K. Schum and Trema orientalis (L) Blume. Intern. J. Chem., 7(2): 21

60. Chu, S.S., Du, S.S. and Liu, Z.L. (2013) Fumigant compounds from the essential oil of Chinese Blumea balsamifera leaves against the Maize Weevil (Sitophilus zeamais). $J$. Chem., 2013: 289874.

61. Kusumawati, I.G.A., Reyunika, I.N., Yogeswara, I.B.A., Mustika, I.G., Adi Putra, I.M.W., Santoso, U. and Marsono, Y. (2019) Effect of loloh sembung (Blumea balsamifera) maturity stage on antioxidant activity. Indones. $J$. Nutr. Diet., 6(1): 1-6.

62. Sakee, U., Maneerat, S., Cushnie, T.P.T. and De-eknamkul, W. (2011) Antimicrobial activity of Blumea balsamifera (Lin.) DC. extracts and essential oil. Nat. Prod. Res., 25(19): 1849-1856.

63. Ragasa, C.Y., Kristin, C., Co, A.L. and Rideout, J.A. (2005) Antifungal metabolites from Blumea balsamifera. Nat. Prod. Res., 19(3): 231-237.

64. Ma, J., Ren, Q., Dong, B., Shi, Z., Zhang, J., Jin, D.Q., Xu, J., Ohizumi, Y., Lee, D. and Guo, Y. (2018) NO inhibitory constituents as potential anti-neuroinflammatory agents for AD from Blumea balsamifera. Bioorg. Chem., 76(2): 449-457.

65. Widhiantara, I.G., Permatasari, A.A.A., Siswanto, F.M. and Dewi, N.P.E. (2018) Leaf extract of sembung (Blumea balsamifera) improves testicular histology of Wistar rats induced high-fat feed. J. Bioteknol. Biosains. Indones., 5(2): 111.

66. Haryono, A., Gunawan, Y.E., Suatma, S., Sumitro, S. and Rahmadu, M. (2013) Anti-fertility effect of various plants at dayak tribe to swiss webster mice. J. Trop. Life Sci., 3(2): 108-112.

67. Norikura, T., Kojima-Yuasa, A., Shimizu, M., Huang, X., Xu, S., Kametani, S., Rho, S.N., Kennedy, D.P. and MatsuiYuasa, I. (2008) Anticancer activities and mechanisms of Blumea balsamifera extract in hepatocellular carcinoma cells. Am. J. Chin. Med., 36(2): 411-424.

68. Roy, K., Saha, S., Biswas, S., Ahmed, W. and Mariappan, G. (2013) In vivo assessment of antidiabetic and antioxidant activities of Blumea balsamifera in streptozotocin-diabetic rats. Res. J. Med. Plant, 7(1): 48-57.

69. Nugroho, A.E., Wijayanti,A., Mutmainah, M., Susilowati, R. and Rahmawati, N. (2016) Gastroprotective effect of combination of hot water extracts of licorice (Glycyrrhiza glabra), pulasari stem bark (Alyxia reinwardtii), and sembung leaf (Blumea balsamifera) against aspirin-induced gastric ulcer model rats. J. Evid. Based Complement. Altern. Med., 21(4): NP77-84.

70. Jiang, Z., Zhou, Y., Ge, W. and Yuan, K. (2014) Phytochemical compositions of volatile oil from Blumea balsamifera and their biological activities. Pharmacogn. Mag., 10(39): 346.

71. Hartanti, D., Dhiani, B.A., Charisma, S.L. and Wahyuningrum, R. (2020) The potential roles of jamu for COVID-19: A learn from the traditional Chinese medicine. Pharm. Sci. Res., 7(4): 12-22.

72. He, C., Yang, P., Wang, L., Jiang, X., Zhang, W., Liang, X., Yin, L., Yin, Z., Geng, Y., Zhong, Z., Song, X., Zou, Y., Li, L. and Lv, C. (2020) Antibacterial effect of Blumea balsamifera DC. essential oil against Haemophilus parasuis. Arch. Microbiol., 202(9): 2499-2508.

73. Alana, A.T., Yuniarni, U. and Hazar, S. (2016) Test the antibacterial activity of the ethanol extract of sembung (Blumea balsamifera L) against acne-causing bacteria Propionibacterium acnes. Pros Farm., 2: 39-44.

74. Jumariswan, J., Sari, I. and Suwarno, R. (2017) Uji antijamur ekstrak etil asetat daun sembung (Blumea balsamifera (L) DC) terhadap pertumbuhan jamur Candida albicans resisten flukonazol. Semin. Nas. Biot., 4(1): 392-396.

75. Yaminulloh, S. and Suprapto. (2017) Formulasi Tablet Hisap Ekstrak Etanol Daun Sembung (Blumea balsamifera L.) Dengan Variasi Konsentrasi Pulvis Gummi Arabicum dan Manitol Serta uji Antijamur Terhadap Candida albicans. Universitas Muhammadiyah Surakarta, Indonesia.

76. Fan, Z.W., Pang, Y.X., Wang, K., Yu, F.L., Wang, D., Yang, Q., Ma, Q.S., Li, X.T., Zou, J., Zhang, W.Q. and Wu, L.F. (2015) Blumea balsamifera oil for the acceleration 
of healing of burn injuries. Molecules, 20(9): 17166-17179.

77. Zhang, B., Tang, M., Zhang, W., Zhangb, C., Ai, Y., Liang, X., Shi, Y., Chen, Y., Zhang, L. and He, T. (2020) Chemical composition of Blumea balsamifera and Magnolia sieboldii essential oils and prevention of UV-B radiation-induced skin photoaging. Nat. Prod. Res., 1-4.

78. Ihsan, S., Sonaru, F., Satriani, H. and Wahyuni, I. (2018) Efek antihiperlidemia obat tradisonal khas suku muna "lansau" berdasarkan parameter kadar LDL. Sainstech Farm., 11(1): 7-11.

79. Arifin, H., Widianingsih, I., Marusin, N. and Andalas, J.F.F. (2007) The effect of acute administration of ethanol extract of Capo leaves (Blumea balsamifera DC) on the morphological and histological features of the liver of male white mice. J. Sains Tek. Far., 12: 82-88.

80. Pang, Y.X., Guan, L.L., Wu, L.F., Chen, Z.X., Wang, K., Xie, X.L., Yu, F.L., Chen, X.L., Zhang, Y.B. and Jiang, Q. (2014) Cloning and sequence analysis of the Blumea balsamifera DC farnesyl diphosphate synthase gene. Genet. Mol. Res., 13(4): 9874-9882.

81. Lalmuanthanga, C., Roy, D.C., Roy, R.K., Sarma, Y., Borah, P., Tamuli, S., Hmarthansanga, L., Shantabi, L. and Devi, I. (2019) Antioxidant activity of methanolic extract of Blumea lanceolaria. Int. J. Chem. Stud., 7(3): 3546-3548.

82. Wang, Y.H. and Zhang, Y.R. (2020) Variations in compositions and antioxidant activities of essential oils from leaves of Luodian Blumea balsamifera from different harvest times in China. PLoS One, 15(6): e0234661.

83. Kimbonguila, A., Matos, L., Petit, J., Scher, J. and Nzikou, J.M. (2019) Effect of physical treatment on the physicochemical, rheological and functional properties of yam meal of the cultivar "Ngumvu" from Dioscorea alata L. of Congo. Int. J. Recent Sci. Res., 8: 22213-22217.

84. Khan, P.A. and Ekka, A. (2018) Antifungal activity of Blumea lacera. Int. J. Adv. Sci. Eng. Technol., 6(4): 6-8.

85. Li, Y., Jalili, R.B. and Ghahary, A. (2016) Accelerating skin wound healing by M-CSF through generating SSEA-1 and -3 stem cells in the injured sites. Sci. Rep., 6(1): 28979.

86. Lutfi, M.F. (2014) Evaluation of the anti-inflammatory effects of Blumea aurita. Glob. J. Med. Res., 13(4): 23-29.

87. Devi, G.B.B. and Amutha, K. (2011) Anti-inflammatory and anti-pyretic activities of Blumea mollis (D. Don) MERR. Res. J. Pharmacogn. Phytochem., 3(1): 14-16.

88. Sullivan, P.J., Agardy, F.J. and Clark, J.J.J. (2005) Living with the risk of polluted water. In: The Environmental Science of Drinking Water. Elsevier, Amsterdam, Netherlands. p143-96.

89. Koriem, K.M.M. (2014) Antihyperlipidemic activity of the medicinal plants among Kadazan and Dusun communities in Sabah, Malaysia: A review. Asian Pac. J. Trop. Biomed., 4(10): 768-779.

90. Rustam, R., Rauf, A., Maryana, N., Pudjianto, P. and Dadang, D. (2012) Leafminer parasitoid community in upland vegetable plantations. J. Nat. Indones., 11(1): 40

91. Deshpande, P. and Gupta, A. (2019) Causes and prevalence of factors causing infertility in a public health facility. $J$. Hum. Reprod. Sci., 12(4): 287.

92. Atanasov, A.G., Waltenberger, B., Pferschy-Wenzig, E.M., Linder, T., Wawrosch, C., Uhrin, P., Temml, V., Wang, L., Schwaiger, S., Heiss, E.H., Rollinger, J.M., Schuster, D., Breuss, J.M., Bochkov, V., Mihovilovic, M.D., Kopp, B., Bauer, R., Dirsch, V.M. and Stuppner, H. (2015) Discovery and resupply of pharmacologically active plant-derived natural products: A review. Biotechnol. Adv., 33(8): 1582-1614.

93. Graudal, N., Leth, P., Mårbjerg, L. and Galløe, A.M. (1991) Characteristics of cirrhosis undiagnosed during life: A comparative analysis of 73 undiagnosed cases and 149 diagnosed cases of cirrhosis, detected in 4929 consecutive autopsies. J. Intern. Med., 230(2): 165-171.

94. Lim, Y.S. and Kim, W.R. (2008) The global impact of hepatic fibrosis and end-stage liver disease. Clin. Liver Dis., 12(4): 733-746.

95. Murray, C.J. and Lopez, A.D. (1997) Alternative projections of mortality and disability by cause 1990-2020: Global burden of disease study. Lancet, 349(9064): 1498-1504.

96. Ali, S.A., Sharief, N.H. and Mohamed, Y.S. (2019) Hepatoprotective activity of some medicinal plants in Sudan. Evid. Based Complement. Altern. Med., 2019: 2196315.

97. Shirode, D.S., Kulkarni, A.V. and Jain, B.B. (2019) Effect of Blumea lacera on tissue, GSH, lipid peroxidation and hepatic cells in ethanol imduced hepatotoxicity in rats. Int. J. Pharm. Pharm. Sci., 11(12): 46-50.

98. Rath, D., Panigrahy, S.R., Panigrahi, S.K., Kar, D.M. and Maharana, L. (2017) Antidiabetic effect of extracts of Blumea lacera DC. in streptozotocin-induced hyperglycemic rats. Int. J. Pharm. Pharm. Sci., 9(10): 218.

99. Mutmainah, Susilowati, R., Rahmawati, N. and Nugroho, A.E. (2014) Gastroprotective effects of combination of hot water extracts of turmeric (Curcuma domestica L.), cardamom pods (Ammomum compactum S.) and sembung leaf (Blumea balsamifera DC.) against aspirin-induced gastric ulcer model in rats. Asian Pac. J. Trop. Biomed., 4(Suppl 1): S500-4.

100. Harwig, J. and Scott, P.M. (1971) Brine shrimp (Artemia salina L.) larvae as a screening system for fungal toxins. Appl. Microbiol., 21(6): 1011-1016.

101. Shaikh, R., Pund, M., Dawane, A. and Iliyas, S. (2014) Evaluation of anticancer, antioxidant, and possible anti-inflammatory properties of selected medicinal plants used in Indian traditional medication. J. Tradit. Complement. Med., 4(4): 253-257.

102. Kelloff, G.J. (1999) Perspectives on cancer chemoprevention research and drug development. Adv. Cancer Res., 78: 199-334.

103. Greenwell, M. and Rahman, P.K.S. (2015) Medicinal plants: Their use in anticancer treatment. Int. J. Pharm. Sci. Res., 6(10): 4103-4112.

104. Hahne, M., Kataoka, T., Schröter, M., Hofmann, K., Irmler, M., Bodmer, J.L., Schneider, P., Bornand, T., Holler, N., French, L.E., Sordat, B., Rimoldi, D. and Tschopp, J. (1998) APRIL, a new ligand of the tumor necrosis factor family, stimulates tumor cell growth. J. Exp. Med., 188(6): 1185-1190.

105. Roth, W., Wagenknecht, B., Klumpp, A., Naumann, U., Hahne, M., Tschopp, J. and Weller, M. (2001) APRIL, a new member of the tumor necrosis factor family, modulates death ligand-induced apoptosis. Cell Death Differ., 8(4): 403-410.

106. Gore, M. and Desai, N.S. (2014) Characterization of phytochemicals and evaluation of anticancer potential of Blumea eriantha DC. Physiol. Mol. Biol. Plants, 20(4): 475-486.

107. Benarba, B. and Pandiella, A. (2020) Medicinal plants as sources of active molecules against COVID-19. Front. Pharmacol., 11: 1189.

108. Amanat, F. and Krammer, F. (2020) SARS-CoV-2 vaccines: Status report. Immunity, 52(4): 583-589.

109. Li, H., Wang, Y.M., Xu, J.Y. and Cao, B. (2020) Potential antiviral therapeutics for 2019 novel coronavirus. Zhonghua Jie He He Hu Xi Za Zhi, 43(3): 170-172.

110. Du, H.Z., Hou, X.Y., Miao, Y.H., Huang, B.S. and Liu, D.H. (2020) Traditional Chinese medicine: An effective treatment for 2019 novel coronavirus pneumonia (NCP). Chin. J. Nat. Med., 18(3): 206-210.

111. Oh, D.Y. and Hurt, A.C. (2016) Using the ferret as an animal model for investigating influenza antiviral effectiveness. Front. Microbiol., 7: 80

112. Friedman, L.M., Furberg, C.D. and DeMets, D.L. (2010) Introduction to clinical trials. In: Fundamentals of Clinical Trials. Springer, New York. p1-18. 